\title{
Non-linear response of light equipment system in a torsional building to bi-directional ground excitation
}

\author{
Abhijit K. Agrawal* \\ Department of Civil Engineering, Indian Institute of \\ Technology, Delhi, India \\ Received 25 July 1997 \\ Revised 9 August 1999
}

Dynamic response of a light equipment item attached to a non-linear and torsionally coupled main system is evaluated under bi-directional earthquake excitation. To account for the effect of translations and torsion, each story of the building is modelled as three degrees-of-freedom (DOFs), with two DOFs for translation in two orthogonal directions and third DOF for torsion. The responses (relative displacement between the equipment system and the floor of the primary system on which the equipment system is mounted and absolute acceleration of the equipment system itself), are determined under random ground motion in two orthogonal directions, which is idealized as a stationary random process represented by a white noise excitation. The responses are obtained by time domain simulation procedure. The response behavior of the light equipment is examined under a set of parametric variations. These parameters include the uncoupled lateral frequency of the primary and the equipment systems, the ratio of uncoupled lateral to rotational frequencies of the primary system, eccentricity ratios of the primary and the equipment systems in $\mathrm{X}$ and $\mathrm{Y}$ directions, damping ratio of the primary and the equipment systems and the mass ratio of the two systems. Results of the study indicate that under some parametric conditions the responses of the equipment system are significantly affected by torsional coupling and non-linearity of the primary system. It is also observed that the responses of the equipment system can be alleviated by increasing the damping ratio of the equipment system.

Keywords: Non-classical damping, non-linear system, torsional coupling, time domain analysis, bi-directional excitation

*Address for correspondence: Abhijit Kumar Agrawal, M.I.G.-2 Padmanabhpur, M.P., Housing Board Colony, Durg, DURG, M.P. 491 004, India. E-mail: abhijit_agrawal@ hotmail.com.

\section{Introduction}

In the last decade, the dynamic analysis of a equipment system mounted on relatively heavy primary system has received much attention $[9,11,15,17]$. The light equipment system is found in many engineering systems such as suspension systems in buildings, nuclear power plants, aircraft, lifeline systems and other important structures. The formulation based on elastic theory, for analysis of the light equipment and primary structural systems, is most desirable for wind and mild earthquake loadings. The primary system generally undergoes non-linear excursion and also exhibit torsional behavior under severe earthquake ground motions. Under such situations, the elastic model leads to inaccurate design of the combined structural systems.

Lin and Mahin [18] found that the responses (relative displacement and absolute acceleration) of the secondary system decrease due to yielding of the primary system. This condition occurs when the fundamental frequency of the secondary system is equal to or more than the fundamental frequencies of the primary structure. Under some parametric conditions of the yielding primary system, amplification in the responses of the secondary system has been observed by Chen and Lutes [8]. For the multi degrees-of-freedom (MDOF) nonlinear primary system, Sewell et al. [23] found that the equivalent SDOF primary system gives incorrect responses of the secondary system, if the primary system undergoes inelastic excursion. They also observed that responses of the secondary system frequently increases in the high frequency range when it is supported on a MDOF primary system.

The above authors had done deterministic analysis for the response calculation of the equipment system. In actual practice, the earthquake excitation is random in nature, so probabilistic analysis should be carried out for correct evaluation of the responses of the equipment system. For very few degrees-of-freedom of the 
nonlinear primary system, the Fokker-Planck equation and closure scheme can effectively be used. The responses of the secondary system mounted over the nonlinear primary system has been solved by Chen and Lutes [7], using equivalent linearization technique developed by Wen [26] and Baber and Wen [5]. They observed that non-linearity of the primary system significantly affects the first passage failure and reliability of the secondary system under normally distributed ground acceleration. Huang and Soong [13] had shown that under some specific conditions, yielding of the primary system alleviates sensitivity of the secondary system. They also used equivalent linearization technique [25] for analysis of the nonlinear primary system and found that the responses of the secondary system has been amplified due to shifting of the primary structural frequencies, under Gaussion white and filtered Gaussion white noise excitations. Behavior of the secondary system has been analyzed by several authors using time history integration technique. Using the same technique Igusa [14], found that yielding of the primary system may result in responses that are small fraction of the corresponding linear responses.

All the above mentioned studies for evaluation of responses of the light equipment system are valid only for symmetric buildings or buildings with very small eccentricity or buildings torsionally very stiff, under uni-directional earthquake excitation. Most of the practical buildings are 3-D un-symmetric buildings [28]. Furthermore, the earthquake excitation is a multidimensional process. Clearly, there is a lack of studies on the subject especially exploring the parametric behavior of equipment system mounted over torsionally coupled yielding primary system under bi-directional ground excitation. Recently, Agrawal and Datta [1] studied the behavior of a secondary system mounted on a torsionally coupled and linear primary system under uni-directional random ground excitation. They [2, 3] also studied the behavior of a secondary system mounted on a torsionally coupled yielding primary system under uni-directional random ground excitation, using both frequency and time domain methods of analysis.

In this paper, stochastic analysis of the equipment system mounted over torsionally coupled and yielding primary structure, is studied under bi-directional ground excitation modelled as a white noise using time domain integration technique. The study is carried out under various important parameters of the equipment and the primary structural systems. In specific term, objectives of the present study are (i) to investigate effect of the bi-directional interaction on yielding of columns of the primary system and response behavior of the equipment system; (ii) to investigate behavior of the light equipment item under various important parametric variations; and (iii) to study the behavior of the equipment system by mounting it on a specific floor level of the primary system.

\section{System model}

Figure 1 shows the system model of an idealized five story building. A cantilever type equipment system is mounted on one of its floor. It is assumed that the cantilever rod is vertically inextensible and has the same flexural stiffness corresponding to the displacement in any direction in the horizontal plane. Similarly, damping of the equipment system is assumed as constant in all the directions. Thus, under the bi-directional seismic excitation of the primary system, the equipment system is excitated and undergoes oscillation in a direction which depends upon motion of the primary system. The normalized eccentricities of the primary system are varied to provide various degrees of torsion in the primary system. Supports of the combined structural systems are excited by random ground excitation in two mutually perpendicular directions (i.e., in $\mathrm{X}$ and Y directions).

Let $K_{\mathrm{p} i}(i=1,4)$ represents the initial lateral stiffness of the $i$-th resisting element, then the total initial stiffness of the primary system in both $\mathrm{X}$ and $\mathrm{Y}$ directions is given by

$$
K_{\mathrm{p}}=\sum_{i=1}^{4} K_{\mathrm{p} i}
$$

and stiffness of the equipment system in any direction is given by $K_{\mathrm{s}}$.

Let $R_{i}$ denotes the distance of the $i$-th resisting element from the center of mass (CM) of the primary system then the total initial torsional stiffness of the primary system, defined about the CM, is given by

$$
K_{\theta}=\sum_{i=1}^{4} K_{\mathrm{p} i} R_{i}^{2}
$$

in which it is assumed that the torsional stiffness of the each individual element is negligible. Eccentricities of the primary system (distance between center of resistance (CR) and CM), in the two orthogonal directions, 
with respect to the CM of the primary system is given by (Fig. 1)

$$
\begin{aligned}
& e_{\mathrm{p} x}=\frac{\sum_{i=1}^{4} K_{\mathrm{p} i} y_{i}}{\sum_{i=1}^{4} K_{\mathrm{p} i}}, \\
& e_{\mathrm{p} y}=\frac{\sum_{i=1}^{4} K_{\mathrm{p} i} x_{i}}{\sum_{i=1}^{4} K_{\mathrm{p} i}}
\end{aligned}
$$

in which $x_{i}$ and $y_{i}$ are the $\mathrm{X}$ and $\mathrm{Y}$ coordinates of the $i$-th element with respect to CM of the primary system.

Eccentricities of the equipment system $\left(e_{\mathrm{s} x}\right.$ and $\left.e_{\mathrm{s} y}\right)$ are taken as a variable for various parametric studies. The two uncoupled frequency parameters of the primary system are defined as

$$
\omega_{\mathrm{p}}=\sqrt{K_{\mathrm{p}} / m_{\mathrm{p}}}
$$

and

$$
\omega_{\theta}=\sqrt{K_{\theta} / m_{\mathrm{p}} r^{2}}
$$

and the natural frequency of the equipment system in any direction is given by

$$
\omega_{\mathrm{s}}=\sqrt{K_{\mathrm{s}} / m_{\mathrm{s}}}
$$

in which $m_{\mathrm{p}}$ and $m_{\mathrm{s}}$ are the masses of the primary and the equipment systems and $r$ is the radius of gyration of the primary mass about the vertical axis through the CM. The frequencies $\omega_{\mathrm{p}}$ and $\omega_{\theta}$ may be interpreted as the natural frequencies of the primary system if they were torsionally uncoupled, i.e., a system with $s_{\mathrm{p} x}$ and $s_{\mathrm{p} y}=0$, but $m_{\mathrm{p}}, K_{\mathrm{p}}$ and $K_{\theta}$ are the same as in the coupled system. The mass ratio $\rho$ is defined by $\rho=m_{\mathrm{s}} / m_{\mathrm{p}}$. The ratio $\omega_{\mathrm{p}} / \omega_{\theta}$ of the primary system are varied to provide different values of the frequency parameters $\omega_{\mathrm{p}}$ and $\omega_{\theta}$. These parameters are taken to be the same in both $\mathrm{X}$ and $\mathrm{Y}$ directions.

\section{Equations of motion}

The equation of motion for the hysteretic primary and the linear equipment systems subjected to bidirectional earthquake excitation, may be written as

$$
\begin{array}{r}
{[\bar{M}]\{\ddot{U}\}+[\bar{C}]\{\dot{U}\}+\{F\}} \\
\quad=-[\bar{M}][\bar{I}]\left\{\ddot{U}_{\mathrm{g}}\right\}=f(t),
\end{array}
$$

where $\left\{\ddot{U}_{\mathrm{g}}\right\}=\left\{\ddot{U}_{\mathrm{g} x}, \ddot{U}_{\mathrm{g} y}\right\}^{\mathrm{T}}$ is the ground acceleration vector. Assuming that the equipment system is mounted on 3rd floor level, the matrices $[\bar{I}]$ and $[\bar{M}]$ are given as

$$
[\bar{I}]=\left[\begin{array}{lllll}
{\left[I_{1}\right]} & {\left[I_{1}\right]} & {\left[I_{2}\right]} & {\left[I_{1}\right]} & {\left[I_{1}\right]}
\end{array}\right]^{\mathrm{T}}
$$

and

$$
[\bar{M}]=\operatorname{diag}\left[\left[M_{1}\right] \quad\left[M_{1}\right] \quad\left[M_{2}\right] \quad\left[M_{1}\right] \quad\left[M_{1}\right]\right]
$$

where

$$
\begin{aligned}
& {\left[I_{1}\right]=\left[\begin{array}{lll}
1 & 0 & 0 \\
0 & 1 & 0
\end{array}\right],} \\
& {\left[I_{2}\right]=\left[\begin{array}{lllll}
1 & 0 & 0 & 1 & 0 \\
0 & 1 & 0 & 0 & 1
\end{array}\right],} \\
& {\left[M_{1}\right]=\operatorname{diag}\left[m_{\mathrm{p}}, \quad m_{\mathrm{p}}, \quad m_{\mathrm{p}} r^{2}\right]}
\end{aligned}
$$

and

$\left[M_{2}\right]=\operatorname{diag}\left[m_{\mathrm{p}}, \quad m_{\mathrm{p}}, \quad m_{\mathrm{p}} r^{2}, \quad m_{\mathrm{s}}, \quad m_{\mathrm{s}}\right]$.

Each floor of the primary system has three DOFs. In local coordinate systems the damping matrix for a story (between any two consecutive floors, say 1st and 2nd) in local coordinate systems, is given by

$$
[C]_{12}=\left[\begin{array}{cc}
{[C]} & -[C] \\
-[C] & {[C]}
\end{array}\right],
$$

where

$$
[C]=\left[\begin{array}{ccc}
\sum C_{\mathrm{p} i} & 0 & \sum C_{\mathrm{p} x \theta} \\
0 & \sum C_{\mathrm{p} i} & \sum C_{\mathrm{p} y \theta} \\
\sum C_{\theta \mathrm{p} x} & \sum C_{\theta \mathrm{p} y} & C_{\theta}
\end{array}\right]
$$

and the damping matrix of the 3rd floor level (where the equipment is mounted), is given by

$$
\begin{aligned}
& {[C]_{3}=\left[\begin{array}{cc}
\sum C_{\mathrm{p} i}+C_{\mathrm{s}} & 0 \\
0 & \sum C_{\mathrm{p} i}+C_{\mathrm{s}} \\
\sum C_{\theta \mathrm{p} x}+C_{\mathrm{s}} e_{\mathrm{s} y} & \sum C_{\theta \mathrm{p} y}+C_{\mathrm{s}} e_{\mathrm{s} x} \\
-C_{\mathrm{s}} & 0 \\
0 & C_{\mathrm{s}}
\end{array}\right.} \\
& \sum C_{\mathrm{p} x \theta}+C_{\mathrm{s}} e_{\mathrm{s} y} \quad-C_{\mathrm{s}} \quad 0 \\
& \sum C_{\mathrm{p} y \theta}+C_{\mathrm{s}} e_{\mathrm{s} x} \quad 0 \quad-C_{\mathrm{s}} \\
& C_{\theta}+C_{\mathrm{s}}\left(e_{\mathrm{s} x}^{2}+e_{\mathrm{s} y}^{2}\right) \quad-C_{\mathrm{s}} e_{\mathrm{s} y}-C_{\mathrm{s}} e_{\mathrm{s} x}, \\
& \left.\begin{array}{ccc}
-C_{\mathrm{s}} e_{\mathrm{s} y} & C_{\mathrm{s}} & 0 \\
-C_{\mathrm{s}} e_{\mathrm{s} x} & 0 & C_{\mathrm{s}}
\end{array}\right]
\end{aligned}
$$


where $C_{\mathrm{p}}, C_{\mathrm{p} x \theta}$ etc. are the elements of damping matrix neglecting the equipment system and $C_{\mathrm{s}}(=$ $\left.2 \xi_{\mathrm{s}} m_{\mathrm{s}} \omega_{\mathrm{s}}\right)$ is the damping for the equipment system. The elements of the damping matrix, concerning the primary system, are determined by assuming the damping matrix of the primary system to be proportional to its mass and initial stiffness matrices. Using the modal damping ratio and the first two undamped mode shapes of the primary system (only), these elements are obtained by standard procedure [20].

The restoring force vector of Eq. (8) is given by

$$
\{F\}=\left[\bar{K}_{\alpha}\right]\{U\}+\left[\bar{H}_{\alpha}\right]\{Z\} .
$$

The non-hysteretic component of the stiffness matrix for a story (between any two consecutive floors, say 1st and 2nd) in local coordinate systems, is given by

$$
\left[K_{\alpha}\right]_{12}=\left[\begin{array}{cc}
{[K]} & -[K] \\
-[K] & {[K]}
\end{array}\right]
$$

where

$[K]=\left[\begin{array}{ccc}\sum \alpha K_{\mathrm{p} i} & 0 & \sum \alpha K_{\mathrm{p} i} y_{i} \\ 0 & \sum \alpha K_{\mathrm{p} i} & \sum \alpha K_{\mathrm{p} i} x_{i} \\ \sum \alpha K_{\mathrm{p} i} y_{i} & \sum \alpha K_{\mathrm{p} i} x_{i} & \sum \alpha K_{\mathrm{p} i}\left(x_{i}^{2}+y_{i}^{2}\right)\end{array}\right]$

and the stiffness matrix for the 3rd floor level (where the equipment is mounted), is given by

$\left[K_{\alpha}\right]_{3}=\left[\begin{array}{ccccc}\sum \alpha K_{\mathrm{p} i}+K_{\mathrm{s}} & 0 & \sum \alpha K_{\mathrm{p} i} y_{i}+K_{\mathrm{s}} e_{\mathrm{s} y} & -K_{\mathrm{s}} & 0 \\ 0 & \sum \alpha K_{\mathrm{p} i}+K_{\mathrm{s}} & \sum \alpha K_{\mathrm{p} i} x_{i}+K_{\mathrm{s}} e_{\mathrm{s} x} & 0 & -K_{\mathrm{s}} \\ \sum \alpha K_{\mathrm{p} i} y_{i}+K_{\mathrm{s}} e_{\mathrm{s} y} & \sum K_{\mathrm{p} i} x_{i}+K_{\mathrm{s}} e_{\mathrm{s} x} & \sum \alpha K_{\mathrm{p} i}\left(x_{i}^{2}+y_{i}^{2}\right)+K_{\mathrm{s}}\left(e_{\mathrm{s} x}^{2}+e_{\mathrm{s} y}^{2}\right) & -K_{\mathrm{s}} e_{\mathrm{s} y} & -K_{\mathrm{s}} e_{\mathrm{s} x} \\ -K_{\mathrm{s}} & 0 & -K_{\mathrm{s}} e_{\mathrm{s} y} & K_{\mathrm{s}} & 0 \\ 0 & -K_{\mathrm{s}} & -K_{\mathrm{s}} e_{\mathrm{s} x} & 0 & K_{\mathrm{s}}\end{array}\right]$

Similarly, the hysteretic component of the stiffness matrix for a story (between two consecutive floors), in local coordinate systems, is given by

$$
\left[H_{\alpha}\right]_{12}=\left[\begin{array}{cc}
{[H]} & -[H] \\
-[H] & {[H]}
\end{array}\right]
$$

where

$$
[H]=\left[\begin{array}{cc}
\sum(1-2 \alpha) K_{\mathrm{p} i} & 0 \\
0 & \sum(1-2 \alpha) K_{\mathrm{p} i} \\
\sum(1-2 \alpha) K_{\mathrm{p} i} y_{i} & \sum(1-2 \alpha) K_{\mathrm{p} i} x_{i}
\end{array}\right]
$$

and the hysteretic component of the stiffness matrix for the 3rd floor level (where the equipment is mounted), is given by

$\left[H_{\alpha}\right]_{3}=\left[\begin{array}{cc}\sum(1-2 \alpha) K_{\mathrm{p} i} & 0 \\ 0 & \sum(1-2 \alpha) K_{\mathrm{p} i} \\ \sum(1-2 \alpha) K_{\mathrm{p} i} y_{i} & \sum(1-2 \alpha) K_{\mathrm{p} i} x_{i} \\ 0 & 0 \\ 0 & 0\end{array}\right]$
The damping matrices $\left([C]_{12},[C]_{3}\right.$ etc. $)$, and the non-hysteretic $\left(\left[K_{\alpha}\right]_{12},\left[K_{\alpha}\right]_{3}\right.$ etc.) and the hysteretic ( $\left[H_{\alpha}\right]_{12},\left[H_{\alpha}\right]_{3}$ etc.) components of the stiffness matrices of the combined structural systems, are arranged according to the global DOFs of the five story structural model (shown in the Fig. 1), to get the compact global damping $[\bar{C}]$ matrix and non-hysteretic $[\bar{K}]$ and hysteretic $[\bar{H}]$ components of the stiffness matrices, using standard procedures $[6,22]$.

If the equipment system is mounted at 3rd floor level, the linear displacement vector $\{U\}$ and the hysteretic displacement vector $\{Z\}$ are given as $(f=$ $1,2,3,4,5)$

$$
\{U\}=\left\{\{U\}_{f}\right\}^{\mathrm{T}}
$$

and

$$
\{Z\}=\left\{\{Z\}_{f}\right\}^{\mathrm{T}} .
$$

The linear displacement vector for the first floor level is given as $(f=1)$

$$
\{U\}_{1}=\left\{U_{\mathrm{p} x 1}, U_{\mathrm{p} y 1}, U_{\theta 1}\right\}
$$



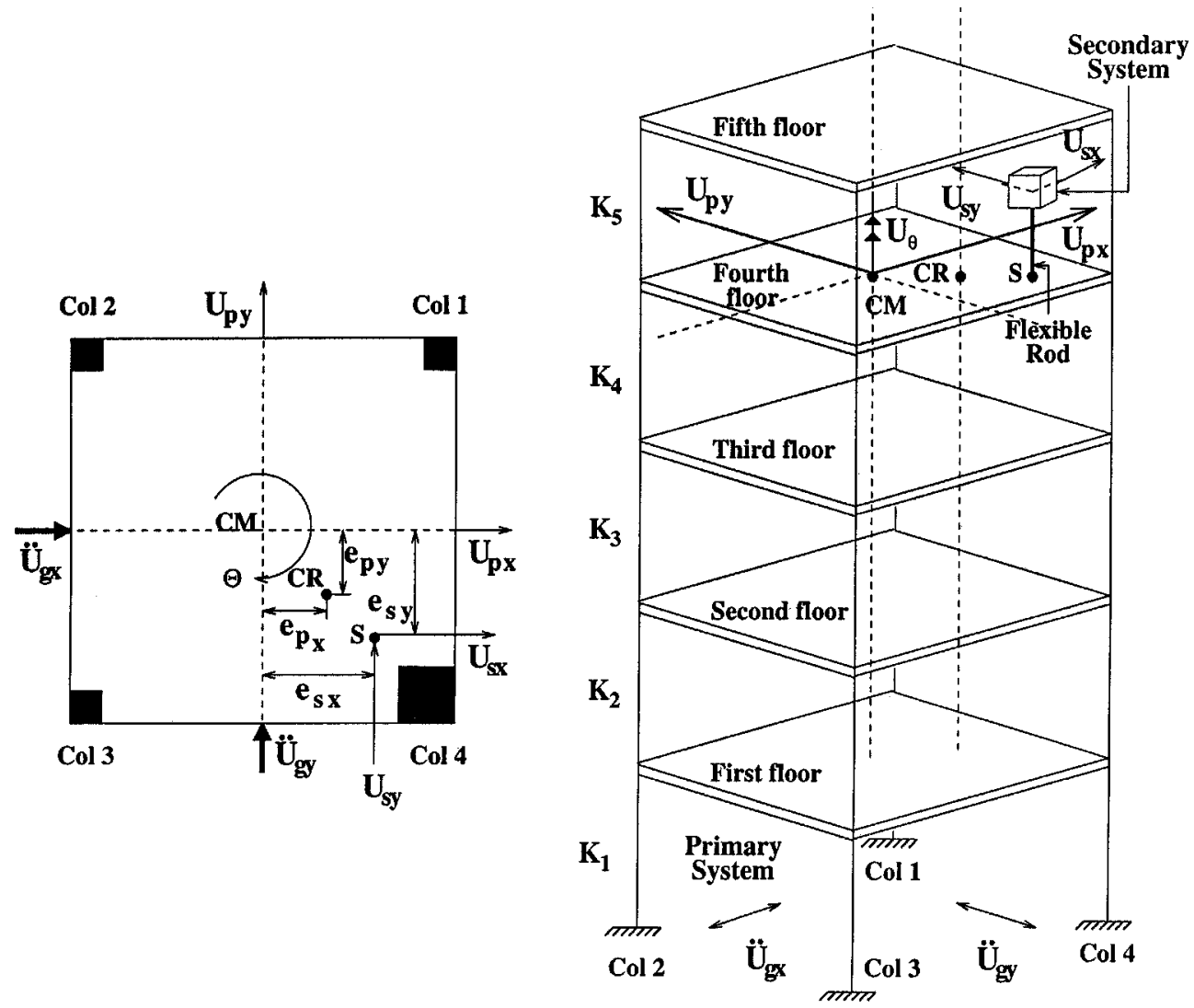

Fig. 1. Structural model.

and the linear displacement vector for the third floor level is given as $(f=3)$

$$
\{U\}_{3}=\left\{U_{\mathrm{p} x 3}, U_{\mathrm{p} y 3}, U_{\theta 3}, U_{\mathrm{s} x}, U_{\mathrm{s} y}\right\} .
$$

The hysteretic displacement vector for the first floor level is given as $(f=1)$

$$
\{Z\}_{1}=\left\{Z_{x 1}, Z_{y 1}\right\}
$$

and the hysteretic displacement vector for the third floor level is given as $(f=3)$

$$
\{Z\}_{3}=\left\{Z_{x 3}, Z_{y 3}\right\} \text {. }
$$

The displacement vectors for the other floors are found by putting the specified floor number in the above Eqs (25) and (26).

The hysteretic components $Z_{j}(j=x, y)$ for the non-linear force deformation relationship of the elements in two orthogonal directions $X$ and $Y$ of a particular floor, are given by following first order non- linear differential equation [27]

$$
\begin{aligned}
\dot{Z}_{x}= & A \dot{U}_{x}-\beta \operatorname{sgn}\left(\dot{U}_{x}\right)\left|Z_{x}\right| Z_{x}-\gamma \dot{U}_{x} Z_{x}^{2} \\
& -\beta \operatorname{sgn} \dot{U}_{y}\left|Z_{y}\right| Z_{x}-\gamma \dot{U}_{y} Z_{x} Z_{y}
\end{aligned}
$$

and

$$
\begin{aligned}
\dot{Z}_{y}= & A \dot{U}_{y}-\beta \operatorname{sgn}\left(\dot{U}_{y}\right)\left|Z_{y}\right| Z_{y}-\gamma \dot{U}_{y} Z_{y}^{2} \\
& -\beta \operatorname{sgn} \dot{U}_{x}\left|Z_{x}\right| Z_{y}-\gamma \dot{U}_{x} Z_{y} Z_{x}
\end{aligned}
$$

in which $\gamma, \beta$, and $A$ are parameters. The parameters $\gamma$ and $\beta$ control the shape of hysteretic loop, $A$ is the restoring force amplitude which controls both stiffness and strength. For nearly elasto-plastic system, these parameters are taken as $A=1.0$, and $\gamma=\beta=0.5$ [19].

\section{Response analysis}

The equation of motion of the combined structural systems (Eq. (8)) can be solved by incremental solu- 
tion choosing suitable time step $(\Delta t)$ for the integration. The resulting incremental effective static equilibrium equation can be expressed as

$$
[\widetilde{K}]\{\Delta U\}=\{\Delta \widetilde{P}\}
$$

and

$$
\left[\bar{H}_{\alpha}\right]\{\Delta Z\}=\left\{\Delta f_{\mathrm{h}}(t)\right\}
$$

the expression for the effective stiffness expression can be written as [10]

$$
[\widetilde{K}]=\left[\widetilde{K}_{\alpha}\right]+\frac{2[\bar{C}]}{\Delta t}+\frac{6[\bar{M}]}{(\Delta t)^{2}}
$$

and the effective load increment for any time $t$ is given by

$$
\begin{aligned}
\{\Delta \widetilde{P}\}= & \{\Delta f(t)\}-\left\{\Delta f_{\mathrm{h}}(t)\right\}+[\bar{M}]\left(\frac{6}{\Delta t}\left\{\dot{U}_{t}\right\}\right. \\
& \left.+3\left\{\ddot{U}_{t}\right\}\right)+[\bar{C}]\left(3\left\{\dot{U}_{t}\right\}+\frac{\Delta t}{2}\left\{\ddot{U}_{t}\right\}\right) .
\end{aligned}
$$

After the calculation of incremental displacement $\{\Delta U\}$ from Eq. (33), the incremental velocity $\{\Delta \dot{U}\}$ may be calculated as

$$
\{\Delta \dot{U}\}=\frac{3}{(\Delta t)}\{\Delta U\}-3\left\{\dot{U}_{t}\right\}-\frac{\Delta t}{2}\left\{\ddot{U}_{t}\right\}
$$

and the acceleration $\{\ddot{U}(t)\}$ is given by

$$
\{\ddot{U}(t)\}=\frac{1}{[\bar{M}]}\left(\left\{f_{\mathrm{I}}\right\}-\left\{f_{\mathrm{D}}\right\}-\left\{f_{K \alpha}\right\}-\left\{f_{\mathrm{h}}\right\}\right),
$$

where $\{\Delta f(t)\}$ is the increment in the earthquake excitation force and $\left\{\Delta f_{\mathrm{h}}(t)\right\}$ is incremental hysteretic force between time $t$ and $t+\Delta t,\left\{f_{\mathrm{I}}\right\}(=[\bar{M}]\{\ddot{U}\})$ is inertial force, $\left\{f_{\mathrm{D}}\right\}(=[\bar{C}]\{\dot{U}\})$ is damping force, $\left\{f_{K \alpha}\right\}\left(=\left[\bar{K}_{\alpha}\right]\{U\}\right)$ is stiffness force (without considering hysteretic effect), and $\left\{f_{\mathrm{h}}\right\}\left(=\left[\bar{H}_{\alpha}\right]\{Z\}\right)$ is hysteretic force. All the above forces are calculated for any time $t$ in order to calculate the acceleration for that time. Since Eq. (8) contains the hysteretic force term, the hysteretic displacement $\left\{\Delta Z_{x}\right\}$ and $\left\{\Delta Z_{y}\right\}$ in two orthogonal directions should be known before solving the equation. The value of these hysteretic displacement components are obtained by solving Eqs (31) and (32) using fourth order Runge-Kutta method. Steps of the procedure are given as: (i) Assume $\{\Delta Z\}_{k}=0(k=1)$ for first iteration (at time $t=0)$.

(ii) Substitute $\{\Delta Z\}_{k}$ in Eq. (8) and solve Eq. (33).

(iii) Calculate velocity vector $\{\Delta \dot{U}\}$ from Eq. (37).

(iv) Compute the revised $\{\Delta Z\}_{k+1}$ (for next cycle) for the time $t=t+\Delta t$ using the fourth order Runge-Kutta method, which is give by

$$
\begin{aligned}
& \{\Delta Z\}_{k+1} \\
& =\frac{\left\{A_{0}\right\}_{k}+2\left\{A_{1}\right\}_{k}+2\left\{A_{2}\right\}_{k}+\left\{A_{3}\right\}_{k}}{6},
\end{aligned}
$$

where

$$
\begin{aligned}
& \left\{A_{0}\right\}_{k}=\Delta t\{\Delta Z\}_{k} \\
& \left\{A_{1}\right\}_{k}=\Delta t\left(\{\Delta Z\}_{k}+\left\{\frac{\left\{A_{0}\right\}_{k}}{2}\right\}\right) \\
& \left\{A_{2}\right\}_{k}=\Delta t\left(\{\Delta Z\}_{k}+\left\{\frac{\left\{A_{1}\right\}_{k}}{2}\right\}\right) \\
& \left\{A_{3}\right\}_{k}=\Delta t\left(\{\Delta Z\}_{k}+\left\{\left\{A_{2}\right\}_{k}\right\}\right)
\end{aligned}
$$

(v) Iterate for next cycle until the following convergence criteria is satisfied

$$
\frac{\left|\{\Delta Z\}_{k+1}\right|-\left|\{\Delta Z\}_{k}\right|}{Z_{m}} \leqslant \text { Tolerance, }
$$

where

$$
Z_{m}=\sqrt{\frac{A}{\beta+\gamma}}
$$

After satisfying the above convergence criteria, the incremental vector $\{\Delta U\}_{k}\{\Delta Z\}_{k}$ and the incremental force vector $\{\Delta \widetilde{P}\}_{1}$ is calculated with help of Eqs (33), (34) and (36). Finally, the acceleration vector $\{\ddot{U}(t)\}$ can be calculated with help of Eq. (38).

The relative displacement $U_{\mathrm{r} j}(t)$ and absolute acceleration $\ddot{U}_{\mathrm{a} j}(t)$ of the equipment system are obtained as $(j=x, y)$

$$
\begin{aligned}
& U_{\mathrm{r} x}(t)=U_{\mathrm{s} x}(t)-U_{\mathrm{p} x}(t)-U_{\theta}(t) e_{\mathrm{s} y}, \\
& U_{\mathrm{r} y}(t)=U_{\mathrm{s} y}(t)-U_{\mathrm{p} y}(t)-U_{\theta}(t) e_{\mathrm{s} x}
\end{aligned}
$$

and

$$
\ddot{U}_{\mathrm{a} j}(t)=\ddot{U}_{\mathrm{s} j}(t)+\ddot{U}_{\mathrm{g} j}(t) .
$$




\section{Parametric study}

The responses (absolute acceleration $\left(\sigma_{\ddot{x}_{\mathrm{a}}} / g=\right.$ $\left.\sigma_{\ddot{U}_{\mathrm{ax}}} / g=\sigma_{\ddot{U}_{\mathrm{a} y}} / g\right)$ and the relative displacement $\left(\sigma_{x_{\mathrm{r}}}=\sigma_{U_{\mathrm{r} x}}=\sigma_{U_{\mathrm{r} y}}\right)$ of the equipment system are influenced by a large number of parameters. These responses are calculated by positioning the equipment system at various floor levels. Effects of only a few important parameters are considered here which predominantly influence torsional and non-linear behavior of the primary system and responses of the equipment system. Theses parameters include the normalized eccentricities of the primary system $\left(e_{\mathrm{p} x} / r\right.$ and $\left.e_{\mathrm{p} y} / r\right)$ and the equipment system $\left(e_{\mathrm{s} x} / r\right.$ and $\left.e_{\mathrm{s} y} / r\right)$ in two orthogonal directions ( $\mathrm{X}$ and $\mathrm{Y}$ ), the uncoupled lateral frequency of the primary $\left(\omega_{\mathrm{p}}\right)$ and the equipment $\left(\omega_{\mathrm{s}}\right)$ systems, the damping ratio of the primary $\left(\xi_{\mathrm{p}}\right)$ and the equipment $\left(\xi_{\mathrm{s}}\right)$ systems, the ratio of uncoupled lateral to rotational frequencies $\left(\omega_{\mathrm{p}} / \omega_{\theta}\right)$ of the primary system and the mass ratio $m_{\mathrm{s}} / m_{\mathrm{p}}$ of the combined system. Specification for the values of the other parameters (held constant throughout) are $\omega_{\mathrm{p}}=4.5 \mathrm{rad} / \mathrm{s}$, $\xi_{\mathrm{p}}=5.0 \%, \xi_{\mathrm{s}}=2.0 \%$ and $r=3.0 \mathrm{~m}$. The hysteretic parameters are taken as $A=1.0, \gamma=\beta=0.5$ and $\alpha=1 / 21$ (for nearly elasto-plastic case). The intensity of white noise input excitation is taken to be the same in both $\mathrm{X}$ and $\mathrm{Y}$ directions and is taken as $0.013 \mathrm{~m}^{2} / \mathrm{s} / \mathrm{rad}$. The combined stiffness of the columns (Fig. 1) in the $\mathrm{X}$ and the $\mathrm{Y}$ directions taken as [24] $K_{1}=6 K_{\mathrm{p}}, K_{2}=5 K_{\mathrm{p}}, K_{3}=4 K_{\mathrm{p}}, K_{4}=3 K_{\mathrm{p}}$ and $K_{5}=2 K_{\mathrm{p}}$. Where $K_{1}, K_{2}$ etc. are shown in the Fig. 1 and $K_{\mathrm{p}}$ is given by Eq. (5). The mass of each floor is taken as $m_{\mathrm{p}}$.

The time history of ground acceleration is simulated from the PSDF of white noise for a record length of 200 seconds. The responses of the equipment system are obtained for the input to the primary system under the simulated ground acceleration.

Figures 2 to 15 show the variation of the normalized standard deviation of the $\left(\sigma_{x_{\mathrm{r}}}\right)$ and $\left(\sigma_{\ddot{x}_{\mathrm{a}}} / g\right)$ of the equipment system (by mounting the equipment system on various floor levels) with normalized eccentricities of the primary and the equipment systems and for strong and weak torsionally coupled primary systems under tuned and detuned conditions.

\subsection{Effect of bi-directional interaction on yielding of columns of the primary system}

Figures 2 and 3 show the effect of bi-directional interaction on yielding of columns of the primary system

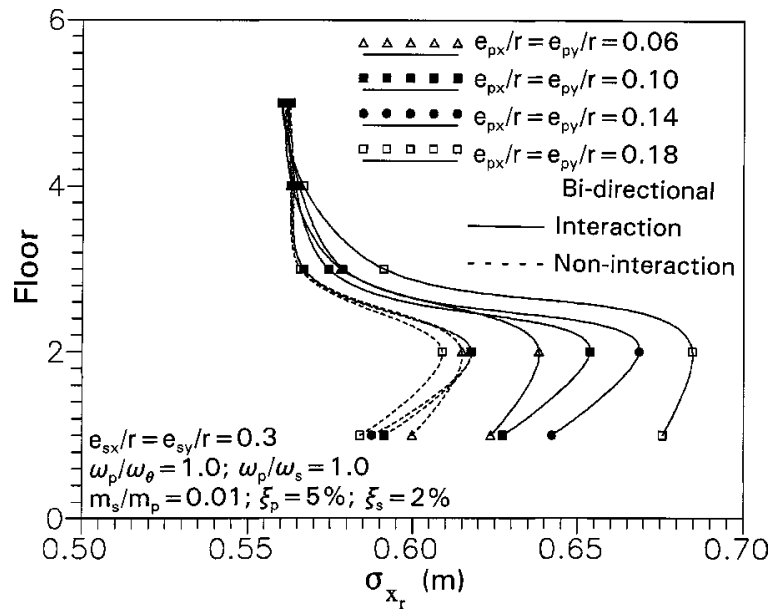

Fig. 2. Variation of $\sigma_{x_{\mathrm{r}}}$ with storey height for various values of $e_{\mathrm{p} x} / r$ and $e_{\mathrm{p} y} / r$; for $m_{\mathrm{s}} / m_{\mathrm{p}}=0.01 ; \omega_{\mathrm{p}} / \omega_{\mathrm{s}}=1.0 ; \omega_{\mathrm{p}} / \omega_{\theta}=1.0$; $e_{\mathrm{s} x} / r=e_{\mathrm{s} y} / r=0.3 ; \xi_{\mathrm{p}}=5 \%$ and $\xi_{\mathrm{s}}=2 \%$ and for bi-directional interaction and non-interaction cases.

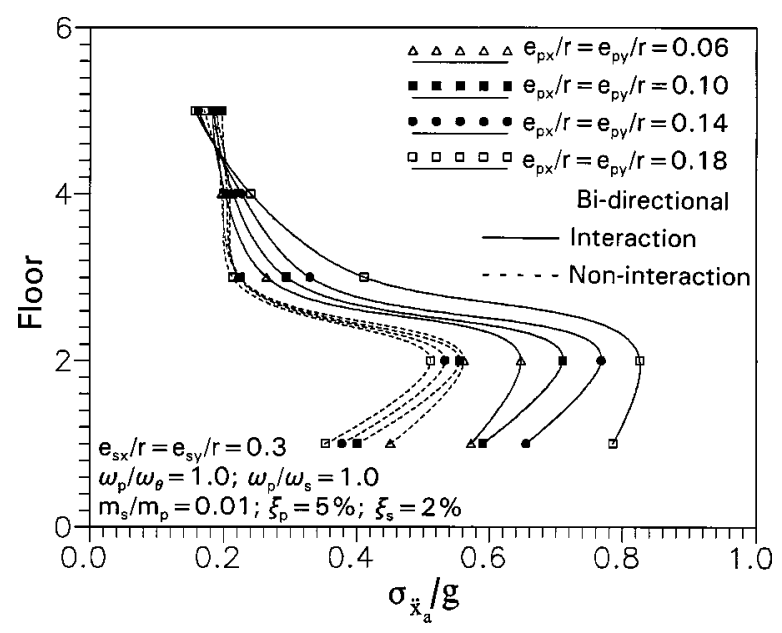

Fig. 3. Variation of $\sigma_{\ddot{x}_{\mathrm{a}}} / g$ with storey height for various values of $e_{\mathrm{p} x} / r$ and $e_{\mathrm{p} y} / r$; for $m_{\mathrm{s}} / m_{\mathrm{p}}=0.01 ; \omega_{\mathrm{p}} / \omega_{\mathrm{s}}=1.0 ; \omega_{\mathrm{p}} / \omega_{\theta}=1.0$; $e_{\mathrm{s} x} / r=e_{\mathrm{s} y} / r=0.3 ; \xi_{\mathrm{p}}=5 \%$ and $\xi_{\mathrm{s}}=2 \%$ and for bi-directional interaction and non-interaction cases.

on responses of the equipment system, for the strong torsionally coupled primary system under the tuned condition. The interaction is considered between lateral and torsional degrees-of-freedom of the primary system, under bi-directional earthquake excitation. It is seen from the figures that the effect of interaction provides higher responses of the equipment system. For both interaction and non-interaction cases, the responses increase when the equipment system is shifted from the 1 st floor level to the 2 nd floor level. Further, decrease in the responses has been observed when the equipment system is shifted from the 2 nd floor level 


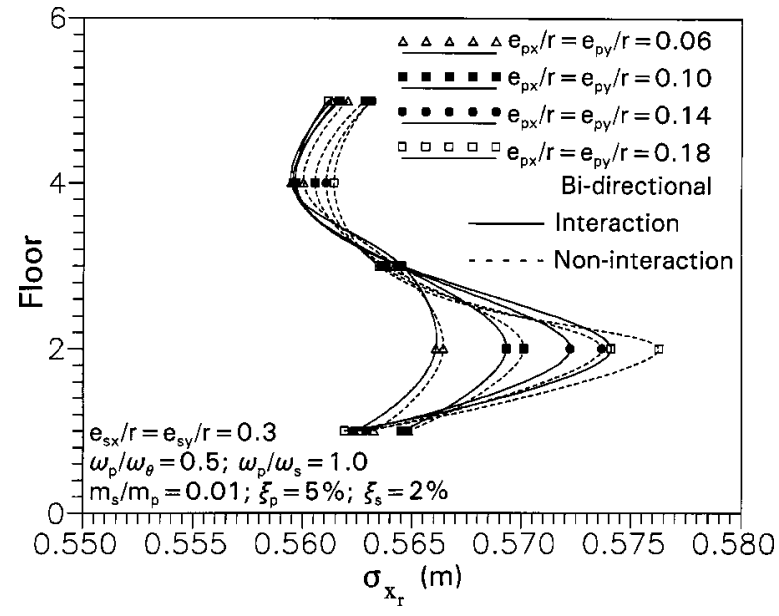

Fig. 4. Variation of $\sigma_{x_{\mathrm{r}}}$ with storey height for various values of $e_{\mathrm{p} x} / r$ and $e_{\mathrm{p} y} / r$; for $m_{\mathrm{s}} / m_{\mathrm{p}}=0.01 ; \omega_{\mathrm{p}} / \omega_{\mathrm{s}}=1.0 ; \omega_{\mathrm{p}} / \omega_{\theta}=0.5$; $e_{\mathrm{s} x} / r=e_{\mathrm{s} y} / r=0.3 ; \xi_{\mathrm{p}}=5 \%$ and $\xi_{\mathrm{s}}=2 \%$ and for bi-directional interaction and non-interaction cases.

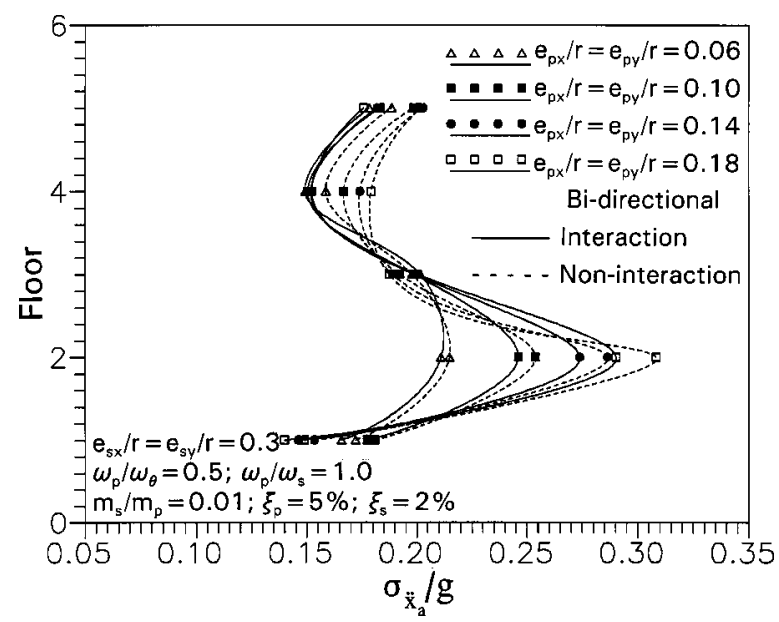

Fig. 5. Variation of $\sigma_{\ddot{x}_{\mathrm{a}}} / g$ with storey height for various values of $e_{\mathrm{p} x} / r$ and $e_{\mathrm{p} y} / r$; for $m_{\mathrm{s}} / m_{\mathrm{p}}=0.01 ; \omega_{\mathrm{p}} / \omega_{\mathrm{s}}=1.0 ; \omega_{\mathrm{p}} / \omega_{\theta}=0.5$; $e_{\mathrm{s} x} / r=e_{\mathrm{s} y} / r=0.3 ; \xi_{\mathrm{p}}=5 \%$ and $\xi_{\mathrm{s}}=2 \%$ and for bi-directional interaction and non-interaction cases.

towards the upper floor levels. For the interaction case, the responses increase by increasing $e_{\mathrm{p} x} / r$ and $e_{\mathrm{p} y} / r$. However, decrease in the responses with increase in $e_{\mathrm{p} x} / r$ and $e_{\mathrm{p} y} / r$ is observed for the non-interaction case.

Reduction in responses of the equipment system (by locating it on the higher floors of the primary system), due to yielding of the first floor of the primary system, had also been observed by Chen and Lutes [8], under uni-directional ground excitation.

Figures 4 and 5 show the same effect for weak torsionally coupled primary system under detuned con-

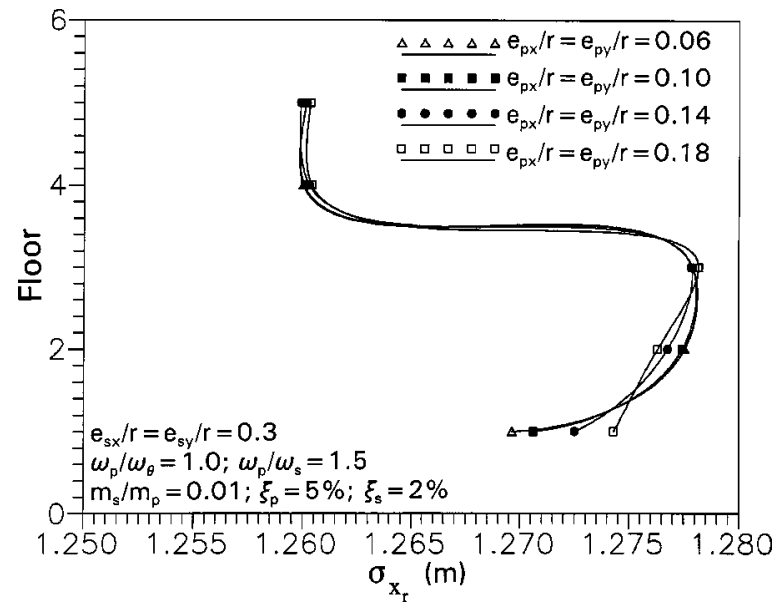

Fig. 6. Variation of $\sigma_{x_{\mathrm{r}}}$ with storey height for various values of $e_{\mathrm{p} x} / r$ and $e_{\mathrm{p} y} / r$; for $m_{\mathrm{s}} / m_{\mathrm{p}}=0.01 ; \omega_{\mathrm{p}} / \omega_{\mathrm{s}}=1.5 ; \omega_{\mathrm{p}} / \omega_{\theta}=1.0$; $e_{\mathrm{s} x} / r=e_{\mathrm{s} y} / r=0.3 ; \xi_{\mathrm{p}}=5 \%$ and $\xi_{\mathrm{s}}=2 \%$.

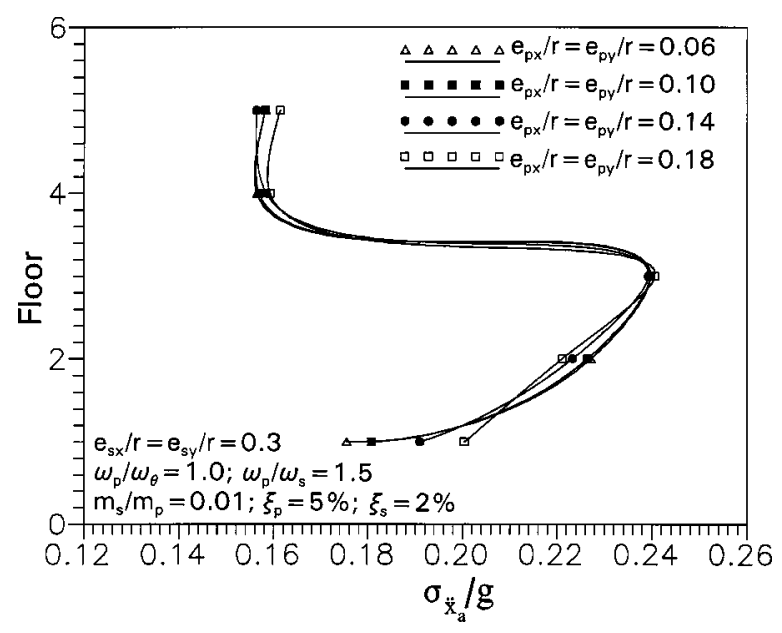

Fig. 7. Variation of $\sigma_{\ddot{x}_{\mathrm{a}}} / g$ with storey height for various values of $e_{\mathrm{p} x} / r$ and $e_{\mathrm{p} y} / r ;$ for $m_{\mathrm{s}} / m_{\mathrm{p}}=0.01 ; \omega_{\mathrm{p}} / \omega_{\mathrm{s}}=1.5 ; \omega_{\mathrm{p}} / \omega_{\theta}=1.0$; $e_{\mathrm{s} x} / r=e_{\mathrm{s} y} / r=0.3 ; \xi_{\mathrm{p}}=5 \%$ and $\xi_{\mathrm{s}}=2 \%$.

dition. Here, the responses are found to be more for non-interaction case than the interaction case. Also for both interaction and non-interaction cases, the responses are found to be maximum if the equipment system is mounted on 2nd floor level and the responses increase by increasing $e_{\mathrm{p} x} / r$ and $e_{\mathrm{p} y} / r$.

\section{Effect of $e_{\mathrm{p} x} / r$ and $e_{\mathrm{p} y} / r$}

Figures 6 to 9 (and previously discussed Figs 2 to 5) show the effect of eccentricity ratios of the primary system on the responses of the equipment system by 


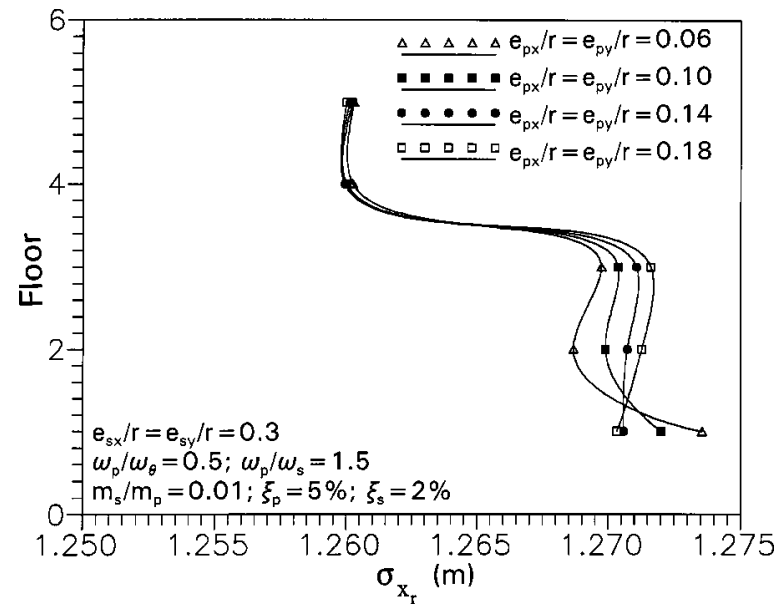

Fig. 8. Variation of $\sigma_{x_{\mathrm{r}}}$ with storey height for various values of $e_{\mathrm{p} x} / r$ and $e_{\mathrm{p} y} / r$; for $m_{\mathrm{s}} / m_{\mathrm{p}}=0.01 ; \omega_{\mathrm{p}} / \omega_{\mathrm{s}}=1.5 ; \omega_{\mathrm{p}} / \omega_{\theta}=0.5$; $e_{\mathrm{s} x} / r=e_{\mathrm{s} y} / r=0.3 ; \xi_{\mathrm{p}}=5 \%$ and $\xi_{\mathrm{s}}=2 \%$.

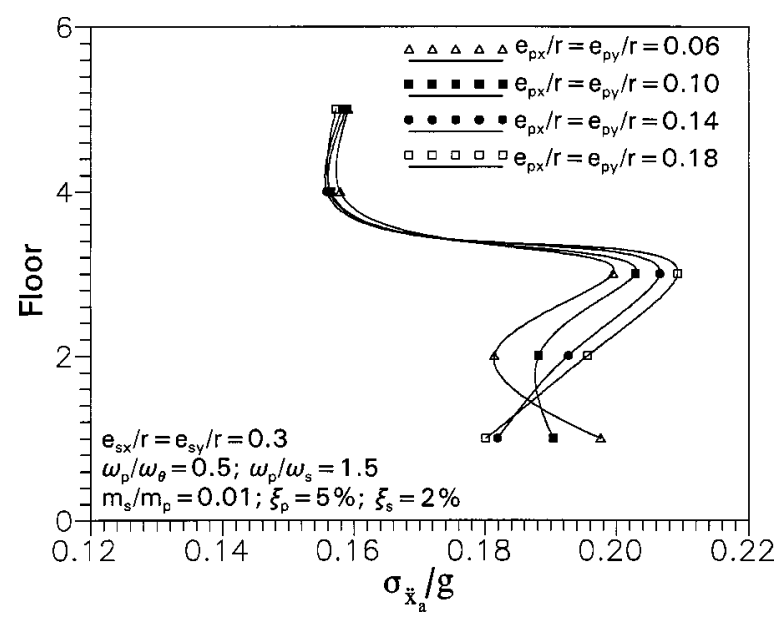

Fig. 9. Variation of $\sigma_{\ddot{x}_{\mathrm{a}}} / g$ with storey height for various values of $e_{\mathrm{p} x} / r$ and $e_{\mathrm{p} y} / r$; for $m_{\mathrm{s}} / m_{\mathrm{p}}=0.01 ; \omega_{\mathrm{p}} / \omega_{\mathrm{s}}=1.5 ; \omega_{\mathrm{p}} / \omega_{\theta}=0.5$; $e_{\mathrm{s} x} / r=e_{\mathrm{s} y} / r=0.3 ; \xi_{\mathrm{p}}=5 \%$ and $\xi_{\mathrm{s}}=2 \%$.

mounting the equipment system at various floor levels, on strong and weak torsionally coupled primary systems under the detuned condition. For the strong torsionally coupled primary system (Figs 6 and 7), the responses increase when the equipment system is shifted from the bottom floor (1st floor) level towards the middle floor (3rd floor) level. Further, decrease in the responses has been observed when the equipment system is shifted towards the upper floor levels. For the weak torsionally coupled primary system (Figs 8 and 9), responses of the equipment system decrease when the equipment system is shifted from the middle floor (3rd floor) level towards the upper floor levels.

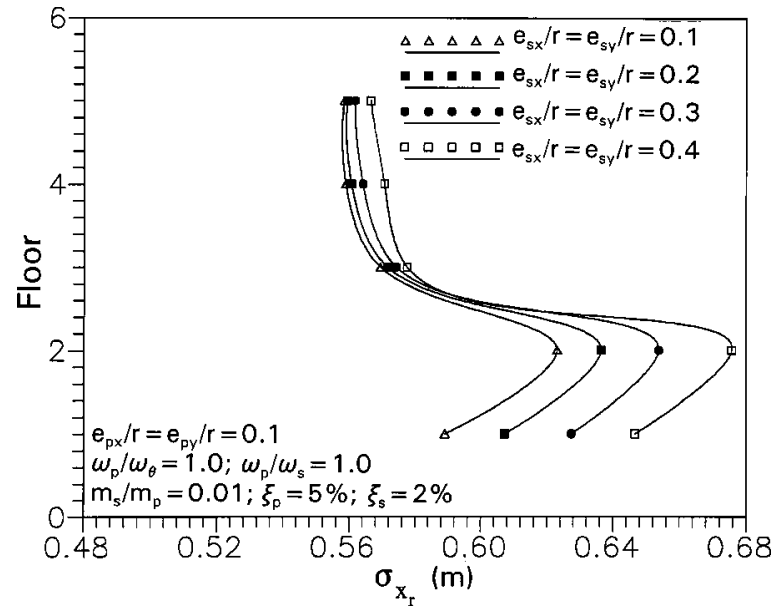

Fig. 10. Variation of $\sigma_{x_{\mathrm{r}}}$ with storey height for various values of $e_{\mathrm{s} x} / r$ and $e_{\mathrm{s} y} / r$; for $m_{\mathrm{s}} / m_{\mathrm{p}}=0.01 ; \omega_{\mathrm{p}} / \omega_{\mathrm{s}}=1.0 ; \omega_{\mathrm{p}} / \omega_{\theta}=1.0$; $e_{\mathrm{p} x} / r=e_{\mathrm{p} y} / r=0.1 ; \xi_{\mathrm{p}}=5 \%$ and $\xi_{\mathrm{s}}=2 \%$.

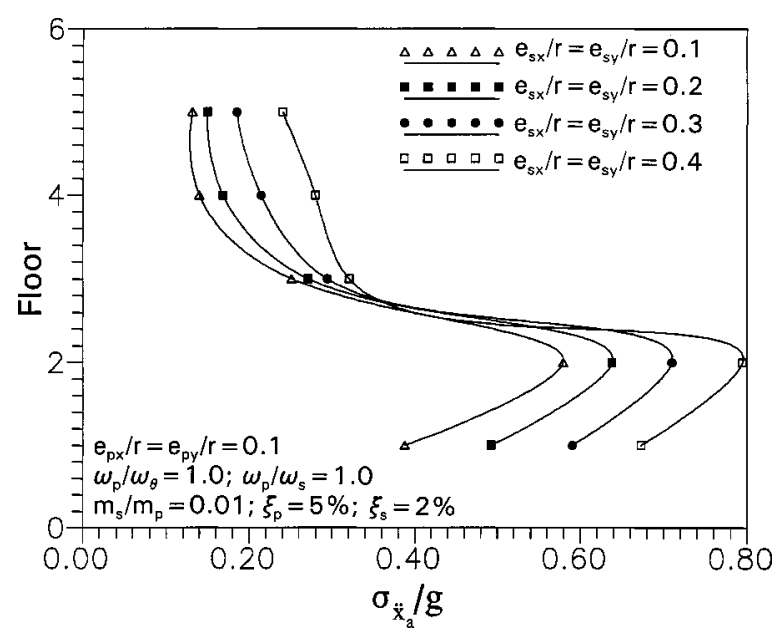

Fig. 11. Variation of $\sigma_{\ddot{x}_{\mathrm{a}}} / g$ with storey height for various values of $e_{\mathrm{s} x} / r$ and $e_{\mathrm{s} y} / r$; for $m_{\mathrm{s}} / m_{\mathrm{p}}=0.01 ; \omega_{\mathrm{p}} / \omega_{\mathrm{s}}=1.0 ; \omega_{\mathrm{p}} / \omega_{\theta}=1.0$; $e_{\mathrm{p} x} / r=e_{\mathrm{p} y} / r=0.1 ; \xi_{\mathrm{p}}=5 \%$ and $\xi_{\mathrm{s}}=2 \%$.

\subsection{Effect of $e_{\mathrm{s} x} / r$ and $e_{\mathrm{s} y} / r$}

Figures 10 to 13 show the variation of responses of the equipment system with $e_{\mathrm{s} x} / r$ and $e_{\mathrm{s} y} / r$ by mounting it on various floor levels, for the strong torsionally coupled primary system under both tuned and detuned conditions. It is observed that under the tuned condition responses are maximum when the equipment system is mounted on the 2nd floor level. Furthermore, responses increase by increasing $e_{\mathrm{s} x} / r$ and $e_{\mathrm{s} y} / r$ (Figs 10 and 11). Under the detuned condition (Figs 12 and 13), reduction in the responses has been observed when the equipment system is shifted from 


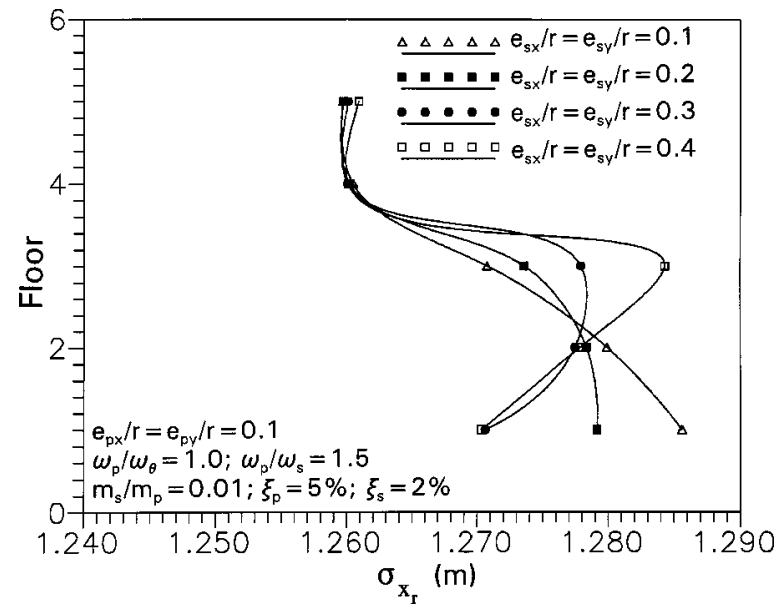

Fig. 12. Variation of $\sigma_{x_{\mathrm{r}}}$ with storey height for various values of $e_{\mathrm{s} x} / r$ and $e_{\mathrm{s} y} / r$; for $m_{\mathrm{s}} / m_{\mathrm{p}}=0.01 ; \omega_{\mathrm{p}} / \omega_{\mathrm{s}}=1.5 ; \omega_{\mathrm{p}} / \omega_{\theta}=1.0$; $e_{\mathrm{p} x} / r=e_{\mathrm{p} y} / r=0.1 ; \xi_{\mathrm{p}}=5 \%$ and $\xi_{\mathrm{s}}=2 \%$.

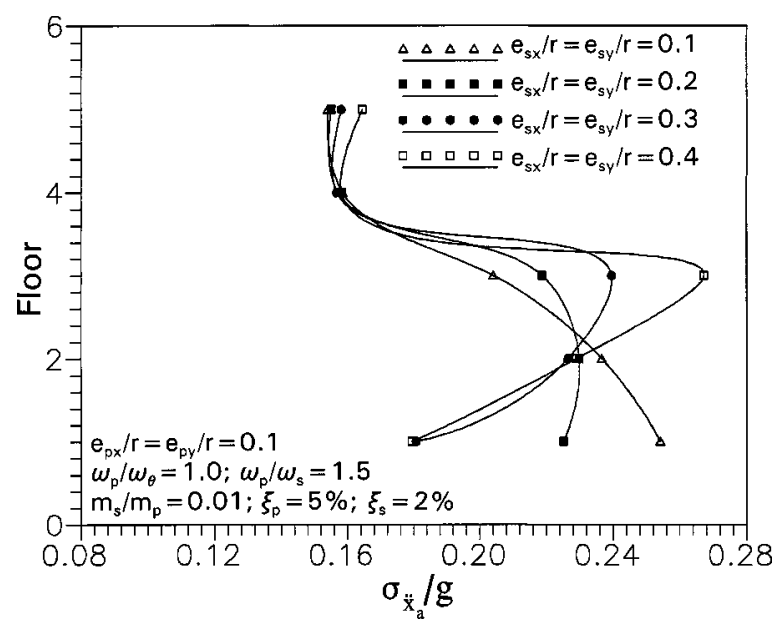

Fig. 13. Variation of $\sigma_{\ddot{x}_{\mathrm{a}}} / g$ with storey height for various values of $e_{\mathrm{s} x} / r$ and $e_{\mathrm{s} y} / r$; for $m_{\mathrm{s}} / m_{\mathrm{p}}=0.01 ; \omega_{\mathrm{p}} / \omega_{\mathrm{s}}=1.5 ; \omega_{\mathrm{p}} / \omega_{\theta}=1.0$; $e_{\mathrm{p} x} / r=e_{\mathrm{p} y} / r=0.1 ; \xi_{\mathrm{p}}=5 \%$ and $\xi_{\mathrm{s}}=2 \%$.

middle floor (3rd floor) level towards the upper floor levels.

\subsection{Effect of the $m_{\mathrm{s}} / m_{\mathrm{p}}$ ratio}

Figures 14 and 15 show the variation of the responses of the equipment system by mounting the equipment system at various floor levels and by changing the mass ratio between the equipment and the primary structural systems, for strong and weak torsionally coupled primary systems under the detuned condition. It is seen that increase in the $m_{\mathrm{s}} / m_{\mathrm{p}}$ ratio decreases the relative displacement of the equipment sys-

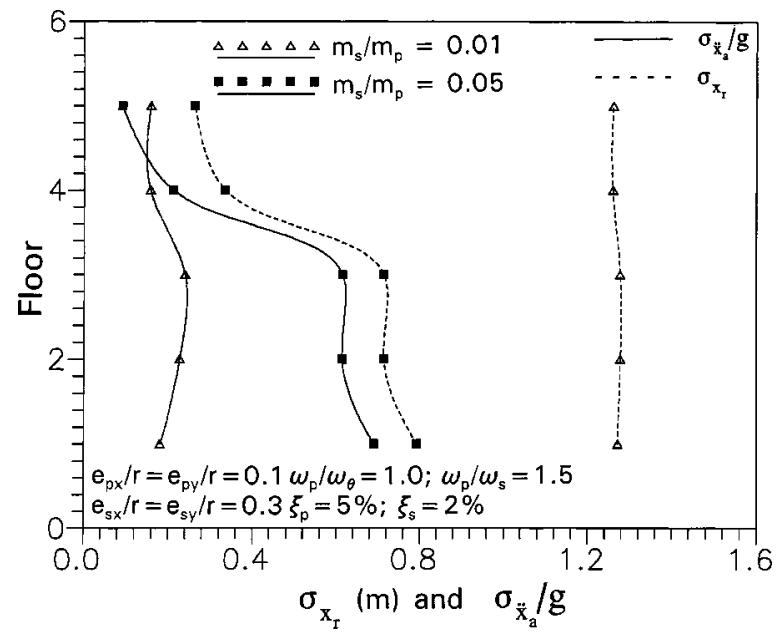

Fig. 14. Variation of $\sigma_{x_{\mathrm{r}}}$ and $\sigma_{\ddot{x}_{\mathrm{a}}} / g$ with storey height for $e_{\mathrm{p} x} / r=e_{\mathrm{p} y} / r=0.1$; for $m_{\mathrm{s}} / m_{\mathrm{p}}=0.01,0.05 ; \omega_{\mathrm{p}} / \omega_{\mathrm{s}}=1.5$; $\omega_{\mathrm{p}} / \omega_{\theta}=1.0 ; e_{\mathrm{s} x} / r=e_{\mathrm{s} y} / r=0.3 ; \xi_{\mathrm{p}}=5 \%$ and $\xi_{\mathrm{s}}=2 \%$.

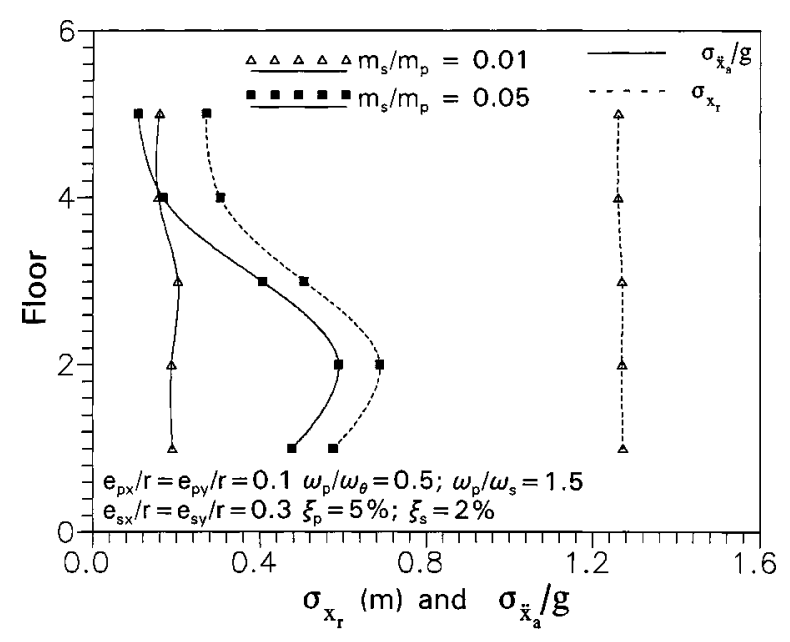

Fig. 15. Variation of $\sigma_{x_{\mathrm{r}}}$ and $\sigma_{\ddot{x}_{\mathrm{a}}} / g$ with storey height for $e_{\mathrm{p} x} / r=e_{\mathrm{p} y} / r=0.1$; for $m_{\mathrm{s}} / m_{\mathrm{p}}=0.01,0.05 ; \omega_{\mathrm{p}} / \omega_{\mathrm{s}}=1.5$; $\omega_{\mathrm{p}} / \omega_{\theta}=0.5 ; e_{\mathrm{s} x} / r=e_{\mathrm{s} y} / r=0.3 ; \xi_{\mathrm{p}}=5 \%$ and $\xi_{\mathrm{s}}=2 \%$.

tem for both cases. However, decrease in the absolute acceleration of the equipment system is found (with increasing in the $m_{\mathrm{s}} / m_{\mathrm{p}}$ ratio) when the equipment system is mounted on the top floor level.

\subsection{Effect of $e_{\mathrm{s} x} / r$ and $e_{\mathrm{s} y} / r$ when the equipment system is mounted on the 2nd floor level}

Figures 16 and 17 show the variation of responses of the equipment system with normalized eccentricities of the equipment system, when it is mounted on the 2nd floor level, for strong and weak torsionally coupled 


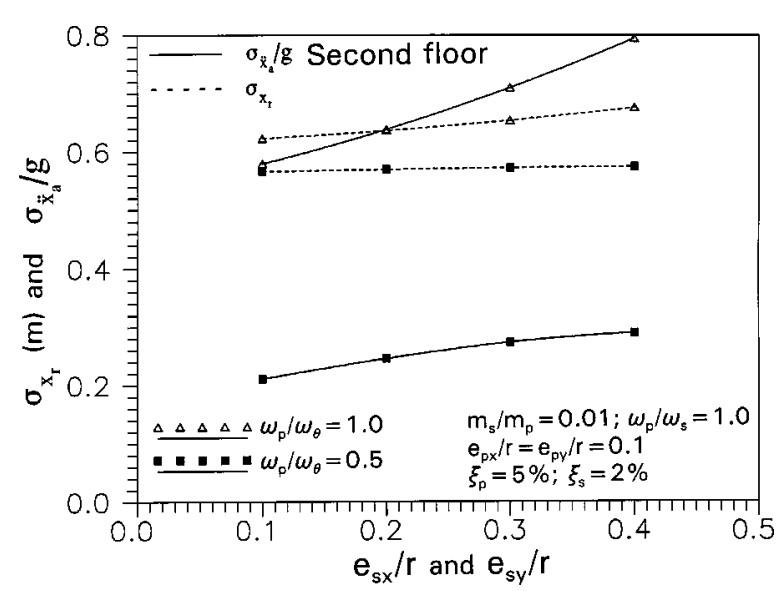

Fig. 16. Variation of $\sigma_{x_{\mathrm{r}}}$ and $\sigma_{\ddot{x}_{\mathrm{a}}} / g$ with $e_{\mathrm{s} x} / r$ and $e_{\mathrm{s} y} / r$; for second floor level, for $m_{\mathrm{s}} / m_{\mathrm{p}}=0.01 ; \omega_{\mathrm{p}} / \omega_{\mathrm{s}}=1.0 ; \omega_{\mathrm{p}} / \omega_{\theta}=1.0$ and $0.5 ; e_{\mathrm{p} x} / r=e_{\mathrm{p} y} / r=0.1 ; \xi_{\mathrm{p}}=5 \%$ and $\xi_{\mathrm{s}}=2 \%$.

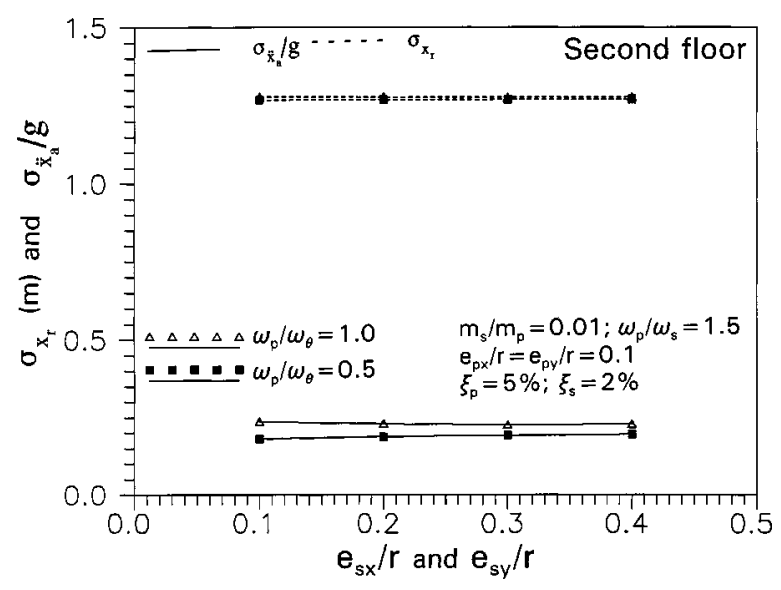

Fig. 17. Variation of $\sigma_{x_{\mathrm{r}}}$ and $\sigma_{\ddot{x}_{\mathrm{a}}} / g$ with $e_{\mathrm{s} x} / r$ and $e_{\mathrm{s} y} / r$; for second floor level, for $m_{\mathrm{s}} / m_{\mathrm{p}}=0.01 ; \omega_{\mathrm{p}} / \omega_{\mathrm{s}}=1.5 ; \omega_{\mathrm{p}} / \omega_{\theta}=1.0$ and $0.5 ; e_{\mathrm{p} x} / r=e_{\mathrm{p} y} / r=0.1 ; \xi_{\mathrm{p}}=5 \%$ and $\xi_{\mathrm{s}}=2 \%$.

primary systems under both tuned and detuned conditions. It is observed from the above figures that the relative displacement is almost insensitive to change in $e_{\mathrm{s} x} / r$ and $e_{\mathrm{s} y} / r$. However, under the tuned condition the absolute acceleration of the equipment system increases with increase in $e_{\mathrm{s} x} / r$ and $e_{\mathrm{s} y} / r$ (Fig. 16). However, under the detuned condition it is almost insensitive to change in $e_{\mathrm{s} x} / r$ and $e_{\mathrm{s} y} / r$ (Fig. 17).

\subsection{Effect of the damping ratio of the equipment system}

Figures 18 and 19 show the variation of the responses with the damping of the equipment system $\left(\xi_{\mathrm{s}}\right)$, for strong and weak torsionally coupled primary

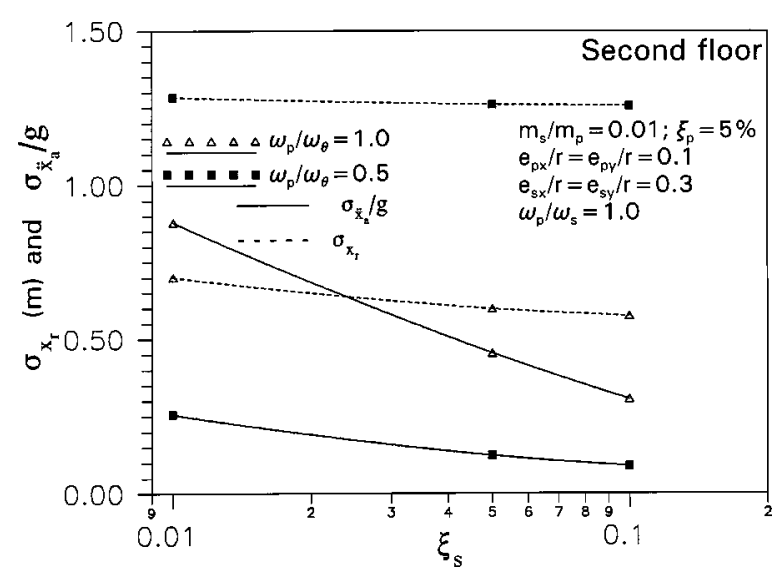

Fig. 18. Variation of $\sigma_{x_{\mathrm{r}}}$ and $\sigma_{\ddot{x}_{\mathrm{a}}} / g$ with $\xi_{\mathrm{s}}$; for second floor level, for $\omega_{\mathrm{p}} / \omega_{\mathrm{s}}=1.0 ; \omega_{\mathrm{p}} / \omega_{\theta}=1.0$ and $0.5 ; \xi_{\mathrm{p}}=5 \%$ $e_{\mathrm{p} x} / r=e_{\mathrm{p} y} / r=0.1, e_{\mathrm{s} x} / r=e_{\mathrm{s} y} / r=0.3$ and $m_{\mathrm{s}} / m_{\mathrm{p}}=0.01$.

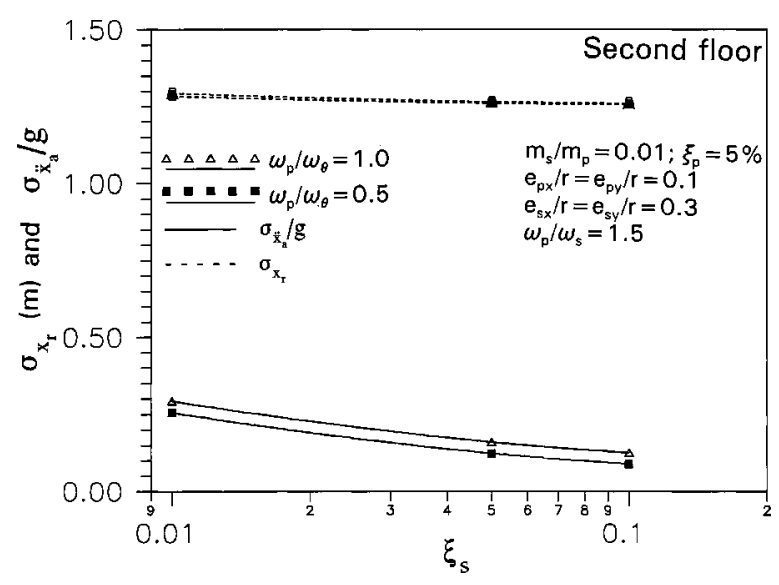

Fig. 19. Variation of $\sigma_{x_{\mathrm{r}}}$ and $\sigma_{\ddot{x}_{\mathrm{a}}} / g$ with $\xi_{\mathrm{s}}$; for second floor level, for $\omega_{\mathrm{p}} / \omega_{\mathrm{s}}=1.5 ; \omega_{\mathrm{p}} / \omega_{\theta}=1.0$ and $0.5 ; \xi_{\mathrm{p}}=5 \%$ $e_{\mathrm{p} x} / r=e_{\mathrm{p} y} / r=0.1, e_{\mathrm{s} x} / r=e_{\mathrm{s} y} / r=0.3$ and $m_{\mathrm{s}} / m_{\mathrm{p}}=0.01$.

systems under both tuned and detuned conditions, when the equipment system is mounted on the 2 nd floor level. The responses decrease with increase in the $\xi_{\mathrm{s}}$. For the detuned condition, it appears that there exists an optimum value of $\xi_{\mathrm{s}}$ for which the $\left(\sigma_{\ddot{x}_{\mathrm{a}}} / g\right)$ becomes a minimum (Fig. 19).

\section{Conclusions}

The seismic behavior of a light equipment system mounted on a torsionally coupled yielding primary structure is investigated for white noise input excitation in two orthogonal directions ( $\mathrm{X}$ and $\mathrm{Y}$ ). Responses of the equipment system are calculated by time integration technique. The response quantities of inter- 
est are standard deviation of the relative displacement between the equipment system and the floor of the primary structure on which the equipment system is mounted and the absolute acceleration of the equipment system itself. The observations made from the parametric studies are as follows:

1. For strong torsionally coupled primary structure under the tuned condition, responses of the equipment is found to be more when the bidirectional interaction is considered in the analysis. However, an opposite trend of the variation of the responses has been observed for the weak torsionally coupled primary structure under tuned condition.

2. For strong and weak torsionally coupled primary systems under the tuned condition, responses of the equipment system attain their peak value if the equipment system is mounted on the middle (2nd) floor level.

3. For both strong and weak torsionally coupled primary systems under the detuned condition, reduction in the responses is observed if the equipment system is shifted from the middle floor level towards the upper floor levels.

4. Except for the weak torsionally coupled primary system under the tuned condition, responses of the equipment system are found to be less if the equipment system is located on the top floor level.

5. The relative displacement is reduced by increasing the $m_{\mathrm{s}} / m_{\mathrm{p}}$ ratio. Reduction in absolute acceleration, with increase in the $m_{\mathrm{s}} / m_{\mathrm{p}}$ ratio is observed only when the equipment system is mounted on the upper floor levels.

6. For location of the equipment on the middle floor level, the absolute acceleration of the equipment system increases with increase in $e_{\mathrm{s} x} / r$ and $e_{\mathrm{s} y} / r$, for both strong and weak torsionally coupled primary systems under the tuned condition. However, the relative displacement is almost insensitive to change in $e_{\mathrm{s} x} / r$ and $e_{\mathrm{s} y} / r$. For both strong and weak torsionally coupled primary systems under the detuned condition, responses are almost insensitive to change in $e_{\mathrm{s} x} / r$ and $e_{\mathrm{s} y} / r$.

7. Responses decrease with increasing in $\xi_{\mathrm{s}}$. For both strong and weak torsionally coupled primary systems under the detuned condition, it appears that there exist an optimum value of $\xi_{\mathrm{s}}$ for which the $\left(\sigma_{\ddot{x}_{\mathrm{a}}} / g\right)$ becomes a minimum, for mounting of the equipment system on the middle floor level.

\section{References}

[1] A.K. Agrawal and T.K. Datta, Behavior of secondary system attached to a torsionally coupled primary system, J. of European Earthquake Engng. 2 (1997), 47-53.

[2] A.K. Agrawal and T.K. Datta, Seismic response of a secondary system mounted on a torsionally coupled non-linear primary system, J. of Earthquake Engng. 2 (1998), 339-356.

[3] A.K. Agrawal and T.K. Datta, Nonlinear response of secondary system due to yielding of torsionally coupled primary system, J. of European Earthquake Engng. (accepted).

[4] A.E. Aktan, D.A.W. Pecknold and M.A. Sozen, Effect of twodimensional earthquake motion on a reinforced concrete column, Civil Engineering Studies, Structural Research Series No. 399, University of Illinois at Urbana-Champaign, Urbana, IL, May 1973.

[5] T.T. Baber and Y.K. Wen, Random vibration of hysteretic degrading systems, J. Engng. Mech., ASCE 107(6) (1981), 10691087.

[6] G.C. Bajoria and A.K. Agrawal, Nonlinear behavior of coupled shear wall and shear core under random ground excitation, The Structural Design of Tall Building (to appear in September 1997 edn).

[7] D.C.K. Chen and L.D. Lutes, Non-normal secondary response due to yielding in a primary structure, Technical report NCEER-90-0002, Nat. Ctr. for Earthquake Engng. Res., Buffalo, N.Y., 1990

[8] D.C.K. Chen and L.D. Lutes, First-passage time of secondary system mounted on yielding structure, J. Engng. Mech., ASCE (1994), 814-834.

[9] Y.O. Chen and T.T. Soong, Stochastic response sensitivity of secondary system to primary structural uncertainties, Struct. Saf. 6(2) (1989), 311-321.

[10] R.W. Clough and J. Penzien, Dynamics of Structures, McGrawHill, New York, 1993.

[11] A.K. Der, L. Jerome and B.N. Omid, Dynamic analysis of light equipment in structure: response to stochastic input, J. Engng. Mech. Div., ASCE (1983), 90-110.

[12] C.D. Huang, W.Q. Zhu and T.T. Soong, Non-linear stochastic response and reliability of secondary system, J. of Engng. Mech., ASCE (1994), 177-196.

[13] C.D. Huang and T.T. Soong, Stochastic sensitivity analysis of nonlinear primary-secondary structural systems, Engng. Structures (1994), 91-96.

[14] T. Igusa, Response characteristics of inelastic 2-DOF primarysecondary system, J. of Engng. Mech., ASCE (1990), 11601174.

[15] R.S. Jangid and T.K. Datta, Spectral analysis of system with non-classical damping using classical mode superposition technique, Earthquake Engng. and Structural Dynamics 22 (1993), 723-735.

[16] R.S. Jangid and T.K. Datta, Performance of base isolation systems for asymmetric building subject to random excitation, Engng. Structure (1995), 443-454.

[17] T. Kubo and J. Penzien, Time and frequency domain analysis of three dimensional ground motions, San Fernando Earthquake, Report No. EERC 76-6, Earthquake Engineering Research Center, University of California, Berkeley, CA, 1976. 
[18] J. Lin and S.A. Mahim, Seismic response of light subsystem on inelastic structures, J. Struct. Engng., ASCE 111(2) (1985), 400-417.

[19] Y.J. Park, Y.K. Wen and H.S. Ang, Random vibration of hysteretic systems under bi-directional ground motions, Earthquake Engng. and Structural Dynamics 14 (1986), 543-557.

[20] M. Paz, Structural Dynamics Theory and Computation, 3rd edn, Van Nostrand-Reinhold, New York, 1991.

[21] D.A. Pecknold, Inelastic structural response to 2D ground motion, J. Engng. Mech. Div. ASCE 100 (1974), 949-963.

[22] S.S. Rao, The Finite Element Method in Engineering, 2nd edn, Pergamon, 1989.

[23] R.T. Sewel, C.A. Cornell, G.R. Toro and R.K. McGuire, A study of factors influencing floor response spectra in nonlinear multi-degree-of-freedom structures, Report No. 82, John A. Blume Earthquake Engng. Ctr., Stanford Univ., Stanford, CA, 1986.
[24] M.P. Singh and G.M. Astiany, Modal time history analysis of non-classically damped structures for seismic motions, Earthquake Engng. and Structural Dynamics 14 (1986), 133-146.

[25] L. Socha and T.T. Soong, Linearization in analysis of nonlinear stochastic systems, Appl. Mech. Rev. 44(10) (1991), 399-422.

[26] Y.K. Wen, Method for random vibration of hysteretic systems, J. of Engng. Mech. Div. (1976), 249-263.

[27] Y.K. Wen, Equivalent linearization for hysteretic systems under random excitation, Trans. of the ASME 47 (1980), 150-154.

[28] Y.B. Yang and W.H. Huang, Equipment structure interaction considering the effect of torsional and base isolation, Earthquake Engng. and Structural Dynamics 27, 155-171. 

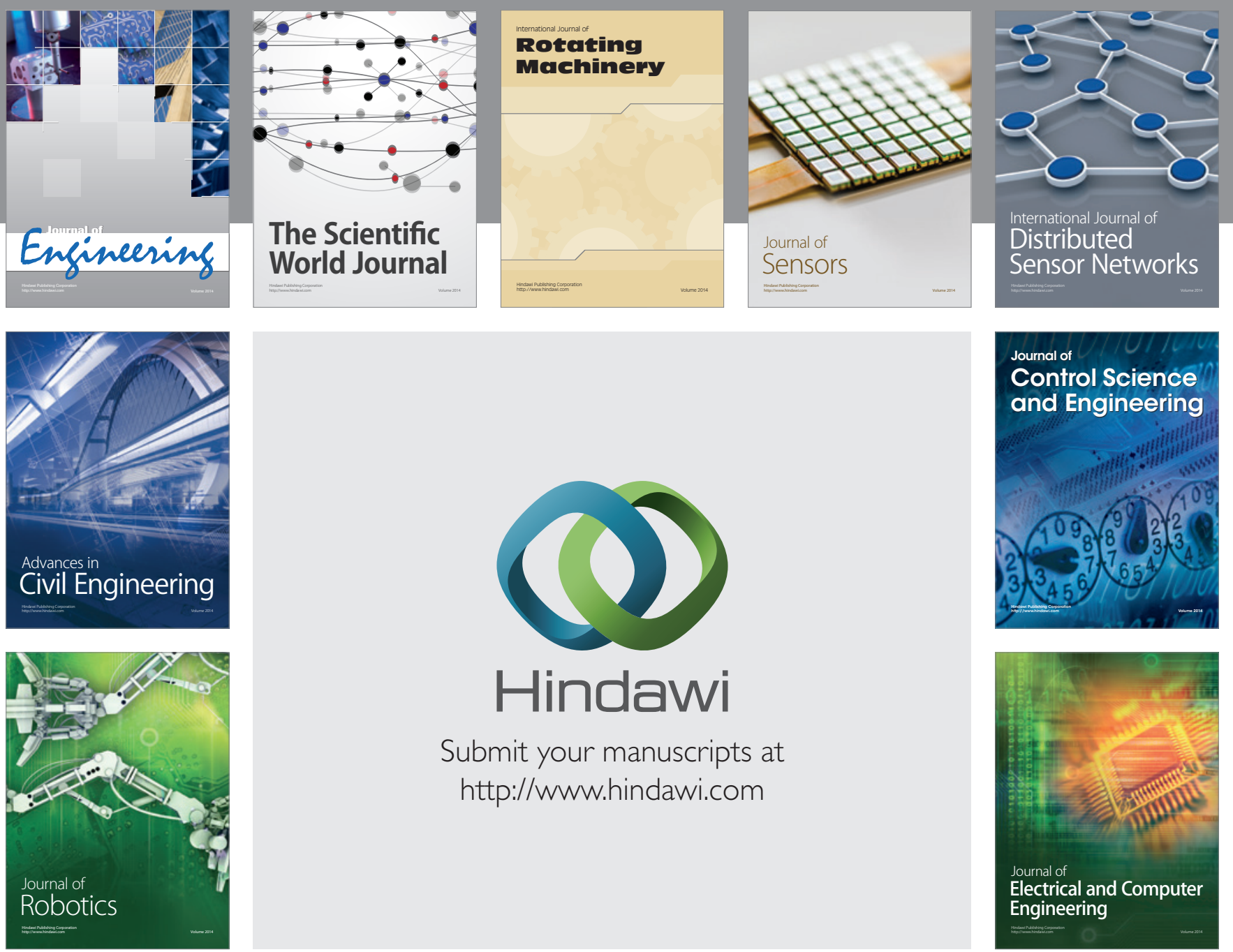

Submit your manuscripts at

http://www.hindawi.com
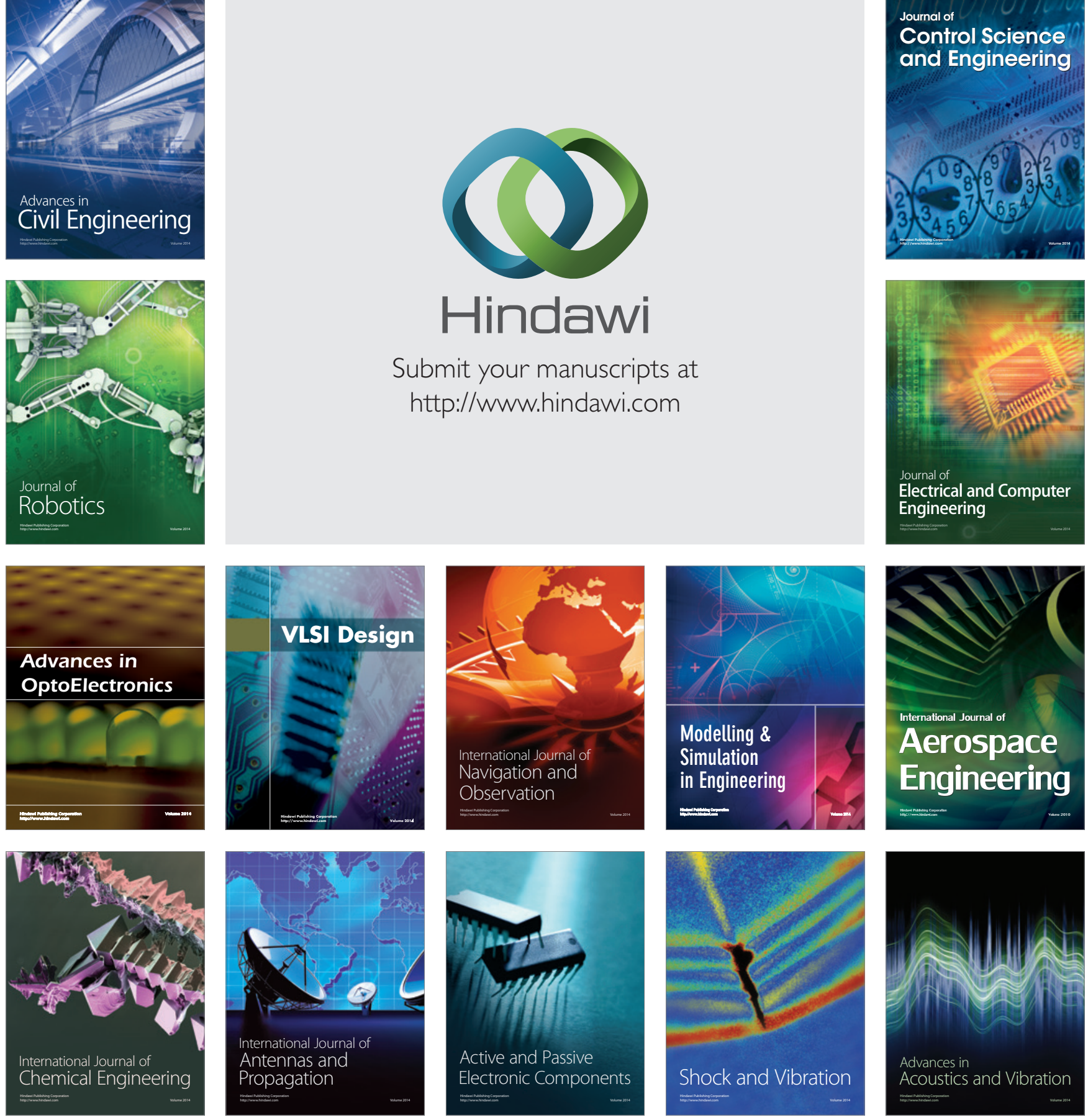